\title{
Psychological intervention with victims of prison violence: a systematic literature review
}

\author{
Rita Conde*, Teresa Souto, and Ana Maria Almeida
}

Faculty of Psychology, Education and Sport, Lusophone University of Oporto (Portugal).

Título: Intervención con víctimas de violencia penitenciaria: revisión sistemática de la literature.

Resumen: Introducción: La victimización penitenciaria ha sido el foco de atención de la comunidad científica con estudios que indican una alta prevalencia y efectos negativos en la salud mental y en la reintegración social de los presidiarios. Sin embargo, existe poca información sobre las intervenciones, por lo que es relevante obtener datos confiables sobre estrategias de intervención que busquen mitigar sus consecuencias y ofrecer apoyo a las víctimas.

Objetivo: realizar una descripción detallada de la literatura sobre intervención psicológica que busca dar respuesta a la victimización en prisión y sus consecuencias.

Método: Revisión sistemática (RS) mediante el método PRISMA-P. La investigación se realizó en 10 bases de datos electrónicas y el proceso de recolección y análisis de datos fue realizado por dos investigadores independientes.

Resultados: Se incluyeron cinco publicaciones, tres estudios cuantitativos y dos artículos teóricos, aunque ninguno se centra específicamente en la intervención con personas sometidas a victimización penitenciaria. Este aspecto se aborda y analiza teóricamente a lo largo de la discusión.

Conclusión: Existen pocas publicaciones sobre intervención con personas victimizadas en prisión y las existentes no enfocan en detalle en la intervención en este tipo de victimización. Sin embargo, se obtuvieron datos relevantes para ser incluidos en futuras propuestas de intervención. Existe consenso en cuanto a la necesidad de adoptar modelos de intervención validados empíricamente, refiriéndose a la Terapia Cognitivo Conductual (TCC), específicamente al Tratamiento Informado por Trauma (TIT).

Palabras clave: Victimización penitenciaria. Presidiarios. Impacto. Intervención. Revisión sistemática.

\section{Introduction}

Over the past two decades, victimization in the prison context has been the focus of attention, especially at an international level (Sánchez \& Wolff, 2018; Daquin et al., 2016; Steiner \& Wooldredge, 2013).

One of the starting difficulties in approaching the phenomenon is related to its definition (Conde \& Abrunhosa Gonçalves, 2014; McGuire, 2018), given that prison victimization assumes different types and forms (e.g. physical., sexual., psychological., attempted or consummated) and can result from the perpetration of several agents (e.g. other prisoners, staff) (Conde \& Abrunhosa Gonçalves, 2014; Wolff et al., 2008). Bearing in mind this difficulty, the World Health Organization definition of violence was adjusted to this context, and prison victimization can be considered as the intentional use of physical force or power over another person (prisoner) or group of people (specific group of prisoners) or

* Correspondence address [Dirección para correspondencia]: Rita Conde, Assistant Professor, Faculty of Psychology, Education and Sport. Lusophone University of Oporto. Rua Augusto Rosa, no 24 | 4000098 Porto (Portugal).E-mail: p5025@ulp.pt; anadias@ulp.pt (Article received: 15-08-2020, revised: 02-10-2020, accepted: 18-11-2020)
Abstract: Background: Prison victimization has been a focus of attention by the scientific community with studies that indicate a high prevalence and negative effects on mental health and social reintegration of prisoners. However, there is few information on intervention responses, so it is relevant to obtain reliable data about intervention strategies that seeks to mitigate its consequences and provide support to victims.

Objective: accomplish a detailed description of the literature on psychological intervention that seeks to respond to victimization in prison and its consequences.

Method: Systematic review (SR) using the PRISMA-P method. The research was carried out in 10 electronic databases and the data collection and analysis process carried out by two independent researchers.

Results: Five publications were included, three quantitative studies and two theoretical articles although none specifically focuses on intervention with individuals subject to prison victimization. This feature is addressed and theoretically analyzed throughout the discussion.

Conclusion: There are few publications on intervention with victims of prison victimization and existing ones do not focus on specific intervention in the context of this type of victimization. However, important guidelines were obtained to be included into future intervention proposals. There is a consensus regarding the need to adopt empirically validated intervention models, referring to the Cognitive Behavior Therapy (CBT), specifically to the Trauma-Informed Treatment (TIT).

Keywords: Prison victimization. Prisoners. Impact. Intervention. Systematic review. community (prison population in general) resulting in physical injury, death, psychological damage, underdevelopment or deprivation (Conde \& Abrunhosa Gonçalves, 2014). Thus, prison victimization can be defined as the experiences of violence suffered by prisoners during the period of imprisonment, ranging from psychological violence to more serious physical violence, including homicide from threat to attempt or consummation.

Several studies indicate the high prevalence of prisoners who suffer victimization inside prisons, either by other prisoners or by professionals (Dias et al., 2019; Wolff et al., 2006). However, there is a great variability in prevalence rates, due to inconsistencies related to the phenomenon conceptualization and to the methodologies used to estimate it. According to Wolff et al. (2009), questions increased specificities accounts for a greater probability of identifying situations of victimization and the different perpetrators. For example, in their study of 7443 inmates in prisons in an American state, a great variability in sexual victimization rates was found, depending on: sex (male: $1.7 \%$ to $10.7 \%$; female: $2.5 \%$ to $26.4 \%$ ); the association between sexual and physical victimization ( $40 \%$ of inmates suffered some form of victimization in the last 6 months).

After reviewing prevalence rates, the majority tends to 
focus on sexual victimization (e.g., Beck et al., 2013; Wolff et al., 2007) and / or physical victimization (Wolff et al., 2009; Steiner \& Wooldredge, 2013), concealing other types of victimization. For example, the study by Wolff et al. (2006) on the rate of sexual victimization reports higher prevalence rates in women $(21.2 \%)$, four and a half times higher than that of men $(4.3 \%)$. Regarding physical victimization, the values are higher, with studies indicating values between $32 \%$ and $66 \%$, as well as when involves material victimization, with rates (e.g. theft) between $18 \%$ and the $48 \%$ (Daquin et al., 2016).

Most prevalence studies focus on the North American context, with fewer studies in other regions. However, the few studies that exist on other continents also indicate disturbing victimization rates. Regarding the European context, studies in southern European countries stand out. For example, in Portugal., a study by Conde et al. (2019a) in prisons situated in the North and Centre regions, indicates that about $25.3 \%$ of the population refer having already suffered some type of violence in prison, namely: physical violence $(44.9 \%)$, sexual violence $(2 \%)$, threats $(6.1 \%)$ and multiple forms of violence $(16.3 \%)$. A Greek study, in prison context, on sexual victimization indicates that about $26 \%$ of prisoners were sexually victimized in prison (Papadakaki et al., 2019). Another study, carried out in Spain, indicates that more than $50 \%$ of prisoners report having suffered some type of victimization in prison and that about $25 \%$ specify having suffered several types of victimization (Sanchez \& Wolff, 2018).

In the African context, studies are even more scarce. The study carried out in several prison establishments in Cape Verde (Dias et al., 2019) stands out, which indicates that about $37.1 \%$ of prisoners suffered some type of victimization and that about $21.4 \%$ indicate having suffered violence in last 12 months. Despite the great variability in prevalence rates, prison victimization is a global phenomenon, assuming disturbing numbers.

From the review of international studies, one can also conclude that prisoners are not just victims of a single type of violence or of a single perpetrator. The investigation has underlined the multiple or cumulative nature of prison victimization, implying, in most cases, the experience of various types of victimization (e.g., Listwan et al., 2012; Listwan et al., 2014; Sanchez \& Wolff, 2018). For example, the retrospective study by Listwan et al. (2012), carried out with 1600 prisoners in Ohio jails after their release, reports the cumulation of various types of victimization in the last 12 months of incarceration: $97.9 \%$ reported vicarious violence (observed theft, physical aggression, verbal aggression or sexual violence) and 58\% reported having been the victim of theft, physical., verbal or sexual violence.

Thus, it should be noted that prison, in addition to being one of the contexts in which there is a greater risk of suffering some type of victimization, constitutes a context of revictimation and cumulative victimization (Sanchez \& Wolff, 2018; Wolff et al., 2009). There is a co-occurrence of different types of victimization (e.g. sexual., physical) and the pos- sibility of its' perpetration by different agents (other prisoners, the staff and / or the institutional structure itself) (Sanchez \& Wolff, 2018). In addition, a crescent number studies are drawing attention to the rates of victimization throughout life, indicating that the prison population has high rates of victimization prior to imprisonment, namely a history of mistreatment, abuse, physical and sexual violence (Sanchez \& Wolff, 2018; Wolff et al., 2009). For example, the study by Sanchez and Wolff (2018) in Spain, indicates that the inmates who are more likely to report victimization in the prison context are also the ones who most report having experienced victimization in childhood and adulthood.

Regarding causes, most of the investigation focuses on prisoners' individual characteristics who are violent in prison (importation theory), suggesting that these individuals reproduce anti-social behavior patterns of behavior and violent attitudes that they already had in their natural life context, victimizing other prisoners (Delisi et al., 2004; McGuire, 2018) The prison context is indicated as a factor for victimization, in which the very structure of the prison organization, the imposition of rules that the prisoners may consider illegitimate and the confrontation with countless deprivations can increase tension and lead to conflict and violence (McGuire, 2018). It should be noted, however, that all the causes mentioned essentially focus on the violence perpetrated by prisoners, so responses are essentially preventive and focused on the control of the violence of prisoners (Byrne \& Hummer, 2008).

Research has also pointed out the negative effects of this victimization, namely on the psychological stability and mental health of prisoners (Conde et al., 2019b; Schappel et al., 2016) as well as in terms of criminal recidivism (Boxer et al., 2009). Several studies reveal its association with problems of psychological adjustment, both during imprisonment and after return to freedom (Boxer et al., 2009; Listwan et al., 2012; Zweig et al., 2015). Specifically, serious problems of psychosocial adjustment are indicated, namely: insecurity, emotional distress, antisocial behaviors, post traumatic stress disorder (Schappel et al., 2016) and substance use disorders (Karlsson \& Zielinski, 2020).

Comparative studies between victimized and nonvictimized prisoners indicate that those who have suffered victimization have higher levels of psychopathological symptoms (Conde et al., 2019a; Conde et al., 2019b), mainly: hostility, paranoid ideation, psychoticism and interpersonal reactivity (Conde et al., 2019b).

Other studies indicate the relationship between prison victimization and an increased risk of criminal recidivism, reporting that victimized prisoners are more hostile and depressed, which increases the likelihood of resorting to violent criminal behaviour when returned to freedom (Zweig et al., 2015). They tend to manifest feelings of hopelessness, low levels of self-control and autonomy, depression, anxiety and feelings of helplessness, later translated into antisocial behaviours (Danquin et al., 2016).

When prison becomes a context of victimization, it plays 
a role opposite to that of resocialization and reintegration, to the extent as it can: (i) generate high levels of aggression and hostility; (ii) enhance violent behaviour and (iii) create psychological and behavioral instability in prisoners, increasing the likelihood of criminal recidivism (Conde \& Abrunhosa Gonçalves, 2014; Zweig et al., 2015).

In view of the high prevalence of the phenomenon and its negative impact, it becomes urgent to develop appropriate prevention and intervention responses. Based on the analysis of the literature, most responses have a preventive nature and focus on the control of prisoners, considering them the main agents of perpetration (e.g., Byrne \& Hummer, 2008; Vigne et al., 2011).

Institutional and prison management interventions are planned, focusing on formal and informal mechanisms for prevention and control of violence (Reisig, 2002) and, mainly, on situational interventions that seek to reduce and / or control circumstances and conditions that facilitate the perpetration of violence (Vigne et al., 2011). Thus, more and better supervision is suggested, placement of surveillance cameras, training of prison officers to intervene in crisis situations (Vigne et al., 2011), reduction of overcrowding, adoption of an appropriate assessment and allocation of prisoners and availability of structured occupation activities, among others (Byrne \& Hummer, 2008).

Regarding interventions that respond to the impact of victimization on prisoners, the accessibility of support in this area seems to be scarce (Conde \& Abrunhosa Gonçalves, 2014). Rehabilitation programs are identified to: (i) prevent recurrence; (ii) solve problem / conflict; (iii) develop adequate and non-violent and / or antisocial social skills (Byrne \& Hummer, 2008).

Summarizing, victimization in the prison context constitutes a serious public health problem, in need of specific interventions to mitigate its consequences on health / psychological adjustment of prisoners and in the social domain (Wolff et al., 2007). It is therefore of utmost importance to obtain accurate and reliable evidence on interventions in this area.

In this context, it is considered crucial to carry out a systematic analysis of the literature on interventions targeted at prisoners who are victims in the prison context, in order to assess: (i) if they exist; (ii) with what objective (s) or focus (s); (iii) the strategies / models used; (iv) the results presented and (v) degree of effectiveness.

In the present work, an SR of psychological interventions directed to the effects of prison victimization with the victimized prisoners is carried out, seeking to identify: the interventions available to this population and assess the theoretical background, as well as the benefits/risks involved. Ultimately, it is intended to obtain updated information, empirically valid, providing guidance and assessment of interventional practices in prison victimization for professionals, making available a starting point for the development of guidelines for interventional practice with prisoners who are victims of prison.

\section{Objective}

Obtain a detailed description of the literature on psychological intervention with prisoners who are victims of violence in the prison context that accounts for an answer to victimization and its consequences.

This objective can be expressed by the following question: What does the literature report on the intervention with prisoners who are victims of violence in the prison context?

\section{Method}

In order to guarantee the quality of the development and writing of this SR review, the guidelines of the Preferred Reporting Items for Systematic reviews and Meta-Analysis Protocol (PRISMA-P) will be adopted, following the checklist of the essential items for this procedure and complemented by the flowchart that describes the 4 phases that are considered (Moher et al., 2015; Shamseer et al., 2015).

\section{Protocol}

A specific protocol for this review was developed according to the parameters proposed by PRISMA-P (Moher et al., 2015; Shamseer et al., 2015) and which will be described in detail.

\section{Eligibility criteria (PICOS)}

P - Type of Participants: Prisoners who are victims of some type of prison violence, aged 18 or over, without any restrictions in terms of other sociodemographic or clinical variables (e.g. sex, sexual orientation, psychopathology, etc.);

I - Type of Interventions: Any psychological intervention focused on the experience of prison victimization and its effects, without restrictions on the theoretical model underlying the intervention or its modality (group vs. individual);

C - Comparison - given the type of studies, it does not apply, with no restrictions at this level;

O - Outcomes: Reference to results/effects/conclusions of the intervention in terms of the psychological adjustment of prisoners, anti-social/violent behaviour and criminal recidivism;

S - Studies (Type of studies): Quantitative and qualitative studies or other works (theoretical reviews) focusing on psychological intervention in prison victims of prisoners. Publications in English, Portuguese and Spanish language for the last 20 years.

Thus, the following inclusion and exclusion criteria are met:

Inclusion criteria:

a) Studies that include inmates victimized in the prison context and on intervention in the context of this victimization; 
b) Quantitative and qualitative studies or other types of work (theoretical reviews);

c) Publications over the past 20 years (2000-2020), given that it is from the first decade of this century that an increasing number of publications on the phenomenon of prison victimization begin to appear;

d) Publications in English, Portuguese and Spanish, in order to reduce search bias;

e) Scientific publications available on the Web, considering that publications from the last decades have some kind of digital record;

f) Studies with prisoners, men and / or women, and aged 18 years or over.

\section{Exclusion criteria:}

a) Publications exclusively on prison victimization that do not include the intervention;

b) Publications on intervention with victimized prisoners, but which does not include prison victimization;

c) Publications only on the prevention of prison victimization;

d) Non-scientific publications (e.g., websites, news, newspapers).

\section{Information sources}

The search was carried out in the following electronic databases:

(1) Specific databases in the scope human and social sciences, including the field of psychology - Sage, Scientific Electronic Library Online (Scielo), and Ebsco. At Ebsco, specifically, Apa PsyInfo and the Psychological and Behavioral Sciences collection were selected;

(2) Databases that include a wider range of scientific fields Pub-med, B-on Online knowledge library (B-on) with duplicates removed;

(3) General data bases, which include scientific journals, theses, abstracts, presentations in congress - DOAJ Directory of Open AcceSS Journals (DOAJ); Periodic Capes; European Collection; World digital library; ACM digital library.

In addition, a more informal search on the Google search engine was also carried out. The survey was performed in the period between 25 January and 25 March 2020 .

\section{Search}

The following search terms were used in Pub-Med, Ebsco and B-on.

1. Psychotherapy or Intervention or Treatment

2. and (Victims or Victimization)

3. and (Inmates or imprisonment or prisoners or incarceration or prisons or offenders or incarceration).
Given the differences in the search tools of the databases used, the terms have been adapted to the other databases. Thus, at Scielo, given the high number of results not related to the theme, the same combination was used, but the option "no abstract" was selected, to limit itself to publications.

At Sage, given the lack of results with the previous combination, we used:

1. Inmates victimization intervention

2. or Inmates violence intervention

In Capes, European Collection, World Digital Library and ACM digital library, given the high number of publications not related to the theme, we resorted to:

1. Inmate victimization (with the "elsewhere" option)

2. and intervention (with the option in the subject)

It is noteworthy that, as a way to validate the process of systematic review, the research strategy was replicated by a peer, coinciding with the results obtained. The research was updated at the end of the review, with no changes in the results.

\section{Selection of publications}

The selection process of publications, that is, from screening to eligibility for inclusion in the SR, was carried out, independently and blindly, by two researchers. Specifically, the process was developed primarily by the researcher responsible for the review and the search criteria and eligibility criteria were explained. The same process was carried out by a second investigator, the disagreements between the investigators were resolved by consensus.

\section{Data collection process}

Considering the eligibility criteria, specifically, the defined inclusion and exclusion criteria, it occurs throughout a five-stage data collection process (cf. Figure 1 - Flowchart).

- Stage 1 - Identification of 274 articles, being 33 duplicates, so they were removed

- Stage 2 - Publications were sorted by title, excluding 184 articles;

- Stage 3 - Screening of the abstract, with 37 publications excluded; of these (11 publications despite addressing prison victimization (prevalence, predictors, etc.) did not include intervention; 15 publications characterized offenders/prisoners, without making any reference to prison victimization and intervention; and 11 publications addressed treatments /interventions or factors that influence it but that did not refer to prison victimization or any other type of victimization;

- Stage 4 - Twenty publications were fully read, carefully considering the analysis of the eligibility criteria. 15 publications were excluded that did not meet the following criteria: one (1) publication that addressed psychological 
intervention with prisoners focused on the risk of recurrence, did not address prison victimization; one (1) publication that reviewed the interventions developed in the context of conjugal and sexual violence, with no reference to victimization in the prison context; seven (7) publications on intervention with prisoners with a history of victimization in the past but who did not consider prison victimization; six (6) publications that addressed intervention with vulnerable groups but made no reference to prison victimization;
- Stage 5 - After reading all the articles, 5 articles were included in this SR.

In the end, an informal search on the Google search engine (prison + victimization + intervention) was carried out, obtaining 132 results. Of these 132, 11 were repeated publications from the databases, 5 were publications focused on the management of violence, 12 results in French and 104 results of websites or non-scientific publications.

Figure 1

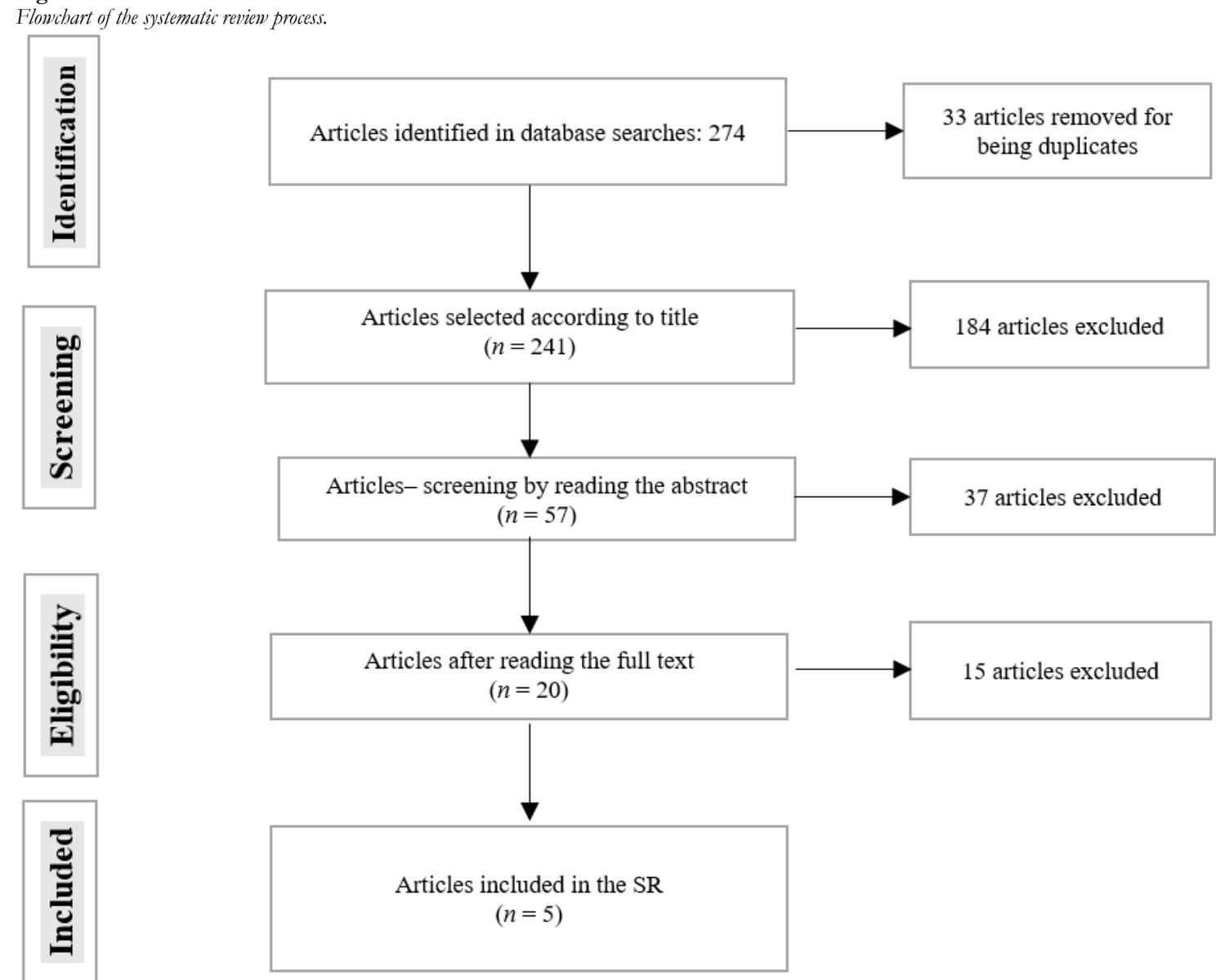

\section{Results}

As described in the data collection process, after analyzing the eligibility criteria, five publications were selected - three quantitative studies and two theoretical publications.

It should be noted that publications on psychological intervention with victimized prisoners started in 2015 (Kupers, 2015), and that the existing publications are limited to prison systems in comparatively more favored countries (in conditions of compliance with human rights, overcrowding, violence ...), namely Spain and Canada, with empirical research and United States with theoretical analysis.
For results presentation, each publication will be characterized and analyzed individually, following the PICOS (see Table 1). Then, a synthesis and integrative analysis is presented.

\section{Individual studies}

Quantitative studies

1.The association between substance use and physical victimization among incarcerated men in Spanish prisons (Sanchez \& Wolff, 2017) 
Quantitative study that analysis the association between substance use and physical victimization (PV) in the prison context. It includes a sample of 2484 male prisoners from 8 (eight) Spanish prisons. Uses two self-report questionnaires as measures, one on the experiences of $\mathrm{PV}$ in the prison context and the other on psychoactive substance use during the last six months.

The results of the study indicate that the rates of PV are higher among prisoners that consume psychoactive substances compared to non-consumer. They conclude that psychoactive substance use is prevalent in the prison context and is highly correlated with physical victimization.

The authors refer to the cross-sectional nature of the investigation as a limitation, as it is impossible to determine a causality, that is, if the use of psychoactive substances precedes PV or vice versa. However, they report that psychoactive substance use appears to be a significant predictor of physical violence during imprisonment. In view of the results, some possible actions are suggested: the application of zero tolerance measures regarding psychoactive substance consumption and a more rigorous and effective control in the distribution of substances/drugs, as a way to reduce the risk of victimization; and, in the case of prisoners in which PV precedes the use of psychoactive substances inside the prison, the suggestion is to integrated them in an evidencebased treatment for substance use and trauma as a more appropriate practice, particularly in the face of Post-Traumatic Stress Disorder (PTSD) symptoms.

\section{Prevalence and Predictors of sexual victimization among incar- cerated men and Women in Spanish Prisons (Sanchéz \& Wolff, 2016)}

The study explores the prevalence of sexual victimization (SV) in Spanish prisons and the association between SV and psychoactive substance use. The results indicate that psychoactive substance use in prison and a childhood history of SV are significantly correlated with SV in prison. The intervention is only mentioned in the discussion, indicating that the integration of treatment for trauma and substance use is considered effective for the prison population. It is stated that this integrated treatment will mainly benefit prisoners with risk factors (childhood history of sexual violence and psychoactive substance abuse problems).

3. Mental Health Screening, Treatment, and Institutional Incidents: A Propensity Score Matched Analysis of Long-Term Outcomes of Screening (Martin et al., 2018)

The study includes 13,281 Canadian prisoners, monitored over 33 months, and seeks to analyze the association between being under treatment and the number of incidents related to health, victimization and violence. Health-related incidents include non-suicidal self-mutilation, non-fatal suicide attempts, non-fatal overdoses and mortality (including deaths by suicide). Violent incidents include fighting between prisoners, assaults and homicides. Victimization includes all violent incidents where the role of the prisoner is that of a victim and not of an instigator of violence.

The results indicate that treatment is associated with lower rates of victimization and violence. It should be noted that this study does not provide information on the type of intervention that prisoners benefited from, referring only to the standard mental health care that exists in Canadian prisons. However, particularly relevant is that the intervention had an effect on reducing victimization experiences, indicating that the intervention, regardless of its modality or approach, can be beneficial.

\section{Theoretical articles}

\section{A gender-specific model of trauma and victimization in incarcer- ated women (Anderson et al., 2019)}

Review article that seeks to understand the role of traumatic experiences and victimization in women prisoners regarding the development of negative cognitions. In this review, it is considered trauma before prison (pre-incarceration trauma - PIT) and trauma associated with experiences of victimization in prison (incarceration-based trauma - IBT). It is stated that both situations of victimization interfere in the prisoners' ability to adopt adequate behaviors oriented towards the future, hindering their social integration. Throughout the article, the need for a specific gender intervention focused on trauma is highlighted, suggesting that mental health services provide a context that considers gender and trauma issues, in order to minimize the effects of post-traumatic responses. However, it should be considered the complete history of victimization and not exclusively or specifically prison victimization.

\section{A community mental health model (Kupers, 2015)}

This study analyses and reviews mental health services in prisons, in the United States, for prisoners with mental health problems. It is emphasized that prisoners with serious mental illnesses are more likely to suffer victimization. Additionally, it is stated that mental health treatments are inadequate and that prisoners are subject to adverse conditions exacerbating existing mental health problems.

In this context, the development of this services requires urgent attention, demanding significant changes. Thus, a set of guidelines are presented and, in the context of victimization issues in the prison context, the authors underline the need for intermediate mental health units/facilities that provide a sufficiently safe context to continue mental health care, in order to avoid victimization and disciplinary problems. Since prisoners with mental health problems are at risk of victimization and are often victims of physical and/or sexual violence and theft, they are described as doubly victimized. Besides that, when these prisoners are placed in isolation cells, they inevitably experience segregation, causing 
psychological suffering and aggravating mental health problems.

Attention is called to traumatic symptoms, resulting from the prisoners' victimization histories (both in life and in prison context), stating that it is crucial to provide adequate interventions to deal with traumatic symptoms, namely PTSD.
This review article, although focused on prisoners with mental health problems, draws attention to issues of victimization, including that perpetrated by the system itself - alerts to the inadequacy of mental health services, to practices that violate human rights and for adverse system conditions.

Table 1

Individual presentation of each of the publications included in the SR.

\begin{tabular}{|c|c|c|c|c|c|c|}
\hline Publication & P-Participants & I - Intervention & C - Comparison & O-Outcomes & $\begin{array}{l}\mathrm{S}-\mathrm{Typo} \text { of } \\
\text { Study }\end{array}$ & Conclusions \\
\hline $\begin{array}{l}\text { Sanchez \& } \\
\text { Wolff, } 2017\end{array}$ & $\begin{array}{l}\text { Male prisoners } \\
\text { in Spanish } \\
\text { prisons }\end{array}$ & $\begin{array}{l}\text { - Seeks to analyse } \\
\text { the association } \\
\text { between psycho- } \\
\text { active substance } \\
\text { use and physical } \\
\text { victimization in } \\
\text { the prison con- } \\
\text { text; } \\
\text { - Does not focus } \\
\text { on intervention. }\end{array}$ & $\begin{array}{l}\text { - Compares in- } \\
\text { mate consumers } \\
\text { with non- } \\
\text { consumer; } \\
\text { - Does not com- } \\
\text { pare intervention } \\
\text { groups. }\end{array}$ & $\begin{array}{l}\text { - } 15.3 \% \text { (non-consumers) } \\
\text { to } 35.5 \% \text { (consumers be- } \\
\text { fore and during impris- } \\
\text { onment) report physical } \\
\text { victimization in the last } 6 \\
\text { months; } \\
\text { - Rates of physical vic- } \\
\text { timization are higher for } \\
\text { prisoners who consume } \\
\text { psychoactive substances } \\
\text { compared to non- } \\
\text { consumers. }\end{array}$ & $\begin{array}{l}\text { Quantitative ar- } \\
\text { ticle, cross- } \\
\text { sectional de- } \\
\text { sign. }\end{array}$ & $\begin{array}{l}\text { - Need for an integrated evi- } \\
\text { dence-based intervention fo- } \\
\text { cused on psychoactive sub- } \\
\text { stance use; } \\
\text { - For prisoners where physical } \\
\text { victimization precedes psycho- } \\
\text { active substance use: need for } \\
\text { integrated evidence-based in- } \\
\text { tervention, focused on sub- } \\
\text { stance use and trauma, namely } \\
\text { symptoms of post-traumatic } \\
\text { stress disorder (PTSD). }\end{array}$ \\
\hline
\end{tabular}

Sanchéz \& Prisoners of - Explores the -Does not com- - The prevalence of SV Quantitative ar-Treatment must integrate Wolff, 2016 both sexes in prevalence of SV pare intervention in the last 6 months was ticle, cross- trauma and psychoactive subof $6.6 \%$, higher in wom- sectional detion between VS en when compared to sign. and psychoactive men $(12.0 \%$ vs. $6.1 \%)$; stance use and is considered effective for the prison population, mainly benefiting individsubstance use;

- Does not focus - Psychoactive substance use in prison and a on intervention. childhood history of SV are significantly correlated with SV in prison. uals who have risk factors (childhood history of sexual violence and substance abuse problems).

Martin, 13,281 inmates Analysed the as- Compares the ef- - Treatment is associated Quantitative ar- Discuss the need to focus efWells, admitted to sociation between fects of the with lower rates of vic- ticle, longitudi- forts on prisoners who have Crocker, Canadian pris- treatment and in- treatment of timization and violence; nal design.

Potter, \& ons and moni- cidents related to prisoners, over - Interventions have less Colman, tored for 33 health, victimiza- time, considering relevant effects on pris2018 months. tion and violence. the results ob- oners who have mental tained in screen- health problems prior to ing and the num- imprisonment, when ber of incidents. compared to those who only show problems after imprisonment.

\begin{tabular}{|c|c|c|c|c|c|c|}
\hline $\begin{array}{l}\text { Kupers, } \\
2015\end{array}$ & $\begin{array}{l}\text { Health services } \\
\text { for prisoners } \\
\text { with mental } \\
\text { health prob- } \\
\text { lems. }\end{array}$ & $\begin{array}{l}\text { - Analysis and re- } \\
\text { view of mental } \\
\text { health services in } \\
\text { US prisons for } \\
\text { inmates with } \\
\text { mental health } \\
\text { problems; } \\
\text { - Does not focus } \\
\text { on intervention. }\end{array}$ & $\begin{array}{l}\text { - Critically ana- } \\
\text { lyse the function- } \\
\text { ing and proce- } \\
\text { dures of mental } \\
\text { health services in } \\
\text { prisons; } \\
\text { - Does not com- } \\
\text { pare intervention } \\
\text { groups. }\end{array}$ & $\begin{array}{l}\text { - Mental health treat- } \\
\text { ments are inadequate; } \\
\text { - Prisoners are subject to } \\
\text { adverse conditions, exac- } \\
\text { erbating mental health } \\
\text { problems. }\end{array}$ & $\begin{array}{l}\text { Theoretical ar- } \\
\text { ticle }\end{array}$ & $\begin{array}{l}\text { - Proposes a set of guidelines } \\
\text { that should be adopted; } \\
\text { - Need for intermediate mental } \\
\text { health units / spaces that pro- } \\
\text { vide a sufficiently safe and ad- } \\
\text { equate context to continue } \\
\text { mental health care, with the } \\
\text { aim of avoiding victimization } \\
\text { and disciplinary problems; } \\
\text { - Draws attention to the trau- } \\
\text { matic symptoms, resulting } \\
\text { from the prisoners' victimiza- } \\
\text { tion histories, both throughout } \\
\text { life and in the prison context; } \\
\text { - Suggests the importance of } \\
\text { providing adequate interven- } \\
\text { tions to deal with traumatic } \\
\text { symptoms, namely PTSD. }\end{array}$ \\
\hline
\end{tabular}




\begin{tabular}{|c|c|c|c|c|c|c|}
\hline Publication & P -Participants & I - Intervention & C - Comparison & $\mathrm{O}$ - Outcomes & $\begin{array}{l}\text { S- Typo of } \\
\text { Study }\end{array}$ & Conclusions \\
\hline $\begin{array}{l}\text { Anderson, } \\
\text { Pitner, \& } \\
\text { Wooten, } \\
2019\end{array}$ & $\begin{array}{l}\text { Women priso- } \\
\text { ners }\end{array}$ & $\begin{array}{l}\text { - Seeks to under- } \\
\text { stand the role of } \\
\text { traumatic situa- } \\
\text { tions and victimi- } \\
\text { zation in women } \\
\text { prisoners; } \\
\text { - Does not focus } \\
\text { on intervention. }\end{array}$ & $\begin{array}{l}\text { - Refers to differ- } \\
\text { ent types of in- } \\
\text { tervention; } \\
\text { - Does not com- } \\
\text { pare intervention } \\
\text { groups. }\end{array}$ & $\begin{array}{l}\text { - Highlights the cogni- } \\
\text { tive-behavioral approach } \\
\text { as having empirical evi- } \\
\text { dence, namely: the TTI } \\
\text { and the prolonged expo- } \\
\text { sure therapy, given the } \\
\text { symptoms of PTSD; } \\
\text { - It is proposed that men- } \\
\text { tal health services consid- } \\
\text { er gender and trauma is- } \\
\text { sues in order to minimize } \\
\text { the effects of post- } \\
\text { traumatic responses. }\end{array}$ & $\begin{array}{l}\text { Theoretical re- } \\
\text { view }\end{array}$ & $\begin{array}{l}\text { - The intervention must con- } \\
\text { sider the differences that wom- } \\
\text { en present in the response to } \\
\text { trauma; } \\
\text { - Importance of developing } \\
\text { therapeutic assessment tools } \\
\text { focused on trauma, as well as } \\
\text { therapeutic approaches that } \\
\text { meet the needs of prisoners } \\
\text { exposed to interpersonal trau- } \\
\text { ma. }\end{array}$ \\
\hline
\end{tabular}

An integrative analysis of the results is now presented, making note that no publication specifically addresses the intervention focused on prison victimization.

Two of the quantitative studies (Sanchez \& Wolff, 2017; Sanchez \& Wolff, 2016) seek to analyze the prevalence of specific types of prison victimization - physical violence (Sanchez \& Wolff, 2017) and sexual violence (Sanchez \& Wolff, 2016) - and both discuss the association of these types of prison victimization with psychoactive substance use problems. Although intervention is only addressed in the discussion of the results and related to the association between victimization and substance use, the relevance of developing evidence-based interventions that integrates trauma and substance use is highlighted.

The third quantitative study (Martin et al., 2018), with a longitudinal design, explores the effects of treatment, in terms of: (i) mental health; (ii) the number of incidents related to physical health, violence and victimization. Even though the focus is not exclusively on victimization, it stresses current symptoms and incidents - from admission to a maximum of 33 months - including victimization, that prisoners refer to in the prison context.

To underline that results indicate that a simple standard treatment (given that they do not specify the type of intervention, referring only to the usual treatment existing in mental health services in the Canadian prison context) is associated with lower rates of victimization. In addition, it should also be noted that the treatment has a more significant effect upon prisoners identified in the screening procedure and without previous mental health problems. Therefore, a reflection should be held on the fact that the prison context is conducive to the emergence of problems, even if the individual does not belong to a risk group, including victimization. So, ultimately, this study suggests that prevention/ intervention in the context of victimization and associated mental health problems, should not be exclusive to risk groups but directed to the prison population in general., increasing its likelihood of effectiveness in prisoners without problems prior to detention. Furthermore, the results underlined the need for specific interventions for prisoners with a history of mental health problems.
In turn, the two theoretical articles focus on intervention, once more not exclusively oriented to prison victimization. One study examines several types of interventions aimed exclusively at victimized women, both throughout life and in the prison context (Anderson et al., 2019). The other article critically analyses mental health services for prisoners with mental health problems (Kupers, 2015), highlighting their inadequacy and even their role as agents of institutional victimization in the prison context. Thus, both articles highlight two specific groups of prisoners vulnerable to victimization women with traumatic and adverse life histories and individuals with mental illness and that traumatic symptoms must be a focus of intervention.

Consequently, the need to provide evidence-based interventions that address trauma, namely PTSD, is stressed. A specific refence is made to the cognitive-behavioral approach (Anderson et al., 2019) with empirical validation supported by several studies As part of this approach, it is advocate the use of TTI and prolonged exposure therapy, mainly to minimize symptoms associated with PTSD. However, it should be noted that no intervention includes prison victimization in isolation even though intervention should aim the effects of victimization throughout life, which includes prison victimization and re-victimization.

\section{Discussion}

From the results of this RS, there is a lack of studies that focus on interventions that specifically address the effects of prison victimization on prisoners and that provide support to prisoners victimized in prison. This observation is verified both at an empirical and at a theoretical level, with no studies including an intervention proposal and that evaluation of its effectiveness, as well as no publications proposing an intervention to undergo future validation. In addition, even from a theoretical or review framework, no publications that analyze or review interventions with prisoners' victims in the prison context were found.

As previously presented, this kind of intervention is addressed in the context of cumulative or lifelong victimization in prisoners and, even in these cases with theoretical articles 
identified, none reported the intervention in prison victimization. Ultimately, prisoners without a history of victimization and experiencing it for the first time in prison would be excluded from this framework and/or the intervention would be inappropriate.

These findings appear somewhat as a paradox, given the number of studies that indicate the high prevalence of the phenomenon (Dias et al., 2019; Wolff et al., 2007) and attest to its negative impact on mental health (Conde et al., 2019b; Schappel et al., 2016) and social reintegration (Zweig et al., 2015) of prisoners. Given that there are specific studies and exclusively dedicated to the prevalence and impact of the phenomenon of prison victimization, the absence of studies on specific measures or intervention proposals for prison victim is inconsistent. More unscientific is this intervention gap, when most studies on the prevalence and impact of the phenomenon call for the need for specific interventions to reduce negative effects on the psychological and social adjustment of prisoners (e.g., Conde \& Abrunhosa Gonçalves, 2014; Wolff et al., 2007).

However, as previously mentioned, although the publications identified do not focus or discuss specific intervention in the context of prison victimization, the analysis in the lifelong victimization context, including the one occurring in the prison context, allows some guidelines/evidences of relevant features that need to be met when planning or developing an intervention proposal to be withdrawn, namely:

- intervention should include the trauma of victimization and minimize associated symptoms (Anderson et al., 2019; Kupers, 2015; Sanchez \& Wolff, 2017; Sanchez \& Wolff, 2016);

in the case of associated substance use problems, they must be addressed during intervention (Sanchez \& Wolff, 2017; Sanchez \& Wolff, 2016);

intervention should customized according to prisoners' specificities - such as gender issues (Anderson et al., 2019), previous history of mental health problems (Kupers, 2015) or current health problems mental arising from the prison context (Martin el al., 2018).

In terms of the therapeutic approaches, there seems to be a consensus on the need to adopt empirically validated models/strategies (e.g. Anderson et al., 2019; Kupers, 2015; Sanchéz \& Wolff, 2017; Sanchéz \& Wolff, 2016). Although not all publications are specific in this scope, not explicitly identifying which models are evidence- based, the literature on victimization and trauma highlights the cognitivebehavioral models as those with greater empirical validity (Condino et al., 2016; Shubina, 2015). Additionally, one of the articles explicitly identifies the cognitive-behavioral model as being clearly the most adequate one (e.g. Anderson et al., 2019), and suggests a specific intervention supported by his model- the Trauma-informed treatment (TIT) - as the most promising one.

It should be noted that TIT differs from specific trauma intervention - while the first informs and is sensitive to the potential problems related to trauma/victimization that may be present in the victims, not focusing exclusively on the sequelae of victimization, the former is expressly designed to treat symptoms related to current or past trauma (Butler et al., 2011).

Thus, TIT seeks to comprehend how violence and victimization structures victims' lives and applies that information to customize intervention to meet the needs and vulnerabilities of the victim. This approach conceptualizes trauma not only as a past event, but as a constitutive or formative feature that may be contributing to the victim's current situation or problems. In this context, the clinical formulation here emphasizes "what happened" and not "what is wrong with the person" (Butler et al., 2011).

In a first glance, it could be pointed out as a limitation to this consensual recommendation that considers the intervention directed to the trauma of victimization, the fact of conceptualizing the experience of prison victimization as necessarily traumatic or inevitably causing symptoms. If the intervention is focused on minimizing or controlling the symptoms associated with the trauma, this limitation is, in fact, evident.

However, if we carry out a careful and detailed analysis of 'TIT's principles (see Elliot et al., 2005, for more), assuming them in "considering the trauma of victimization", we can verify that it can also apply to asymptomatic or "nontraumatized" victims. Specifically, TIT postulates the following principles:

- Recognize the impact of violence and victimization on the subject's development and coping strategies (this impact is not necessarily negative);

- Identify recovery from trauma as the main objective (when there are symptoms associated with the trauma);

- Adopt a model of empowerment or training;

- Maximize victims' choices and perception of control;

- Develop a collaborative relationship;

- Provide a context of respect, security and acceptance for victims;

- Emphasize the victim's strengths, conveying the adaptive nature of the symptoms (if present) and resilience;

- Minimize the possibilities of re-traumatization or revictimization;

- Valuing contextual aspects, understanding the victims in the context of their life and culture experiences;

- Make an effort to involve the victims in the design and evaluation of the intervention.

Thus, since is regarding the cognitive-behavioral model that more empirical evidence has been produced and given the recommendations of the studies included in this SR, it can be concluded that, in fact, the cognitive behavioral strategies may be those with greater sustainability, adequacy and efficiency. However, it is emphasized that these interventions should be customized (e.g., victims with or without a previous history of victimization) and their responses to victimization (there may be victims with symptoms associated 
with trauma or not), so the option for TIT seems appropriate. This adequacy is supported by several studies (see Janssen, 2018, for more) that signal the integration of TIT in offenders' treatment plan as relevant, considering that a history of adversity and/ or victimization is present in many prisoners. However, we believe that the effectiveness of TIT should constitute a line of future research, as it is considered complementary to the cognitive-behavioral model.

Finally, according to present review, future research should fill in the gap of proposals focused on prison victimization promoting their empirical validation and an evaluation of its' effectiveness. Another challenge for research has to do with the need to compare different models of intervention and modalities according to victims' specificities and regarding treatment outcomes.

It should be noted that although studies on prison victimization took place in the first decade of this century, it is only from 2015 onwards that interest in the intervention with victims is identified in the literature. Furthermore, research on the theme focuses mainly on western and economically more favoured countries, in conditions of compliance with human rights, overcrowding, and violence, namely in Canada, United States and Spain. Finally, it seems that

\section{References}

*Anderson, D.J., Pitner, R.O., \& Wooten, N.R. (2019). A gender-specific model of trauma and victimization in incarcerated women. Journal of Human Behavior in the Social Environment, 30 (2),191-212. https://doi.org/10.1080/10911359.2019.1673272

Beck, A. J., Berzofsky, M., Caspar, R., \& Krebs, C. (2013). Sexual victimization in prisons and jails reported by inmates, 2011-2012: National Inmate Survey (Research Report No. NCJ 241399). https://www.bjs.gov/content/pub/pdf/ svpjri1112.pdf

Boxer, P., Middlemass, K., \& Delorenzo, T. (2009). Exposure to Violent Crime During Incarceration: Effects on Psychological Adjustment Following Release. Criminal Justice and Behavior, 36(8), 793-807. https://doi.org/10.1177\%2F0093854809336453

Butler, L. D., Critelli, F. M., \& Rinfrette, E. S. (2011). Trauma-informed care and mental health. Directions in Psychiatry, 31(3), 197-212.

Byrne, J., \& Hummer, D. (2008). Examining the impact of institutional culture on prison violence and disorder. An evidence-based review. In J.M. Byrne, D. Hummer \& F. Taxman (Eds), The culture of prison violence (pp. 40-66). Pearson.

Conde, R., \& Abrunhosa Gonçalves, R. (2014). Vitimação cumulativa em contexto prisional: Modelos explicativos e respostas de intervenção [Cumulative victimization in a prison context: Explanatory models and intervention responses]. In. M. Matos (Coord.), Vitimas de crime e violência: Práticas de intervenção (pp. 161-177). Psiquilíbrios.

Conde, R., Dias, J., Souto, T., \& Gamito, P. (2019a). Mental Health and victimization: an exploratory study in prisons of Cape Verde. Journal of Psychology and Clinical Psychiatry, 10 (5), 172-179. https://doi.org/10.15406/ipcpy.2019.10.00649

Conde, R., Moura, A., Pinto, R., Ribeiro, P., \& Vieira, R. (2019b). Vitimação na prisão e Saúde mental (Victimization in prison and mental health]. In R.R. Ferreira, \& M. Moreira (Coord.), Saúde Mental da Comunidade - Trauma e Resiliência (pp. 176-181). O Gaiense.

Condino, V., Tanzilli, A., Speranza, A. M., Lingiardi, V. (2016). Therapeutic interventions in Intimate Partner Violence: An overview. Research in Psychotherapy: $\quad$ Psychopathology, 19 (2):79-88. https://doi.org/10.4081/ripppo.2016.241

Daquin, J. C., Daigle, L. E., \& Listwan, S. J. (2016). Vicarious Victimization in Prison: Examining the Effects of Witnessing Victimization While In- there are no research teams with a line of work developed on this topic (except for Sánchez and Wolff, 2016, 2017) and, even less, an international collaborative work that seeks to assess and intervene on the phenomenon in an articulated approach, to develop international guidelines for intervention.

Recalling the question that guided this RS- What does the investigation and literature inform about the intervention with prisoners' victims of violence in the prison context? the answer points to reduced information on the subject, which leads to a speculative or merely theoretical analysis of the intervention. If, on the one hand, the literature on prison victimization has increased, intervention in this area has been neglected or relegated to the background. In view of the scarcity of "results" and as a conclusion, the main contribution of this work is to draw attention to the urgency in the development of empirical and experimental studies in the context of intervention with prisoners' victims of violence in prison. Considering the documented impact in terms of their psychological adjustment and, mainly, in terms of their social reintegration and risk of recurrence, it is not only the wellbeing of prisoners that is at stake, but also that of society in general.

carcerated on Offender Reentry. Criminal Justice and Behavior, 43 (8), 1018-1033. https://doi.org/10.1177\%2F0093854816650479

DeLisi, M., Berg, M. T., \& Hochstetler, A. (2004). Gang members, career criminals, and prison violence: Further specification of the importation model of inmate behavior. Criminal Justice Studies, 17,4, 369-383. https://doi.org/10.1080/1478601042000314883

Dias. J., Conde, A.R., \& Souto, T. (2019). Victimization and psychopathology prevalence's in a sample of inmates in Cape Verde. EC Psychology and Psychiatry, 9 (8), 981-992.

Elliott, D. E., Bjelajac, P., Fallot, R. D., Markoff, L. S., \& Reed, B. G. (2005). Trauma-Informed or Trauma-Denied: Principles and Implementation of Trauma-Informed Services for Women. Journal of Community Psychology, 33(4), 461-477. https://doi.org/10.1002/jcop.20063

Janssen, E. (2018). Integrating Trauma Informed Care into the Treatment of Adult Male Sex Offenders: A Systematic Review. https://sophia.stkate.edu/msw_papers/826

Karlsson, M. E., \& Zielinski, M. J. (2020). Sexual Victimization and Mental Illness Prevalence Rates Among Incarcerated Women: A Literature Review. Trauma and violence, 21 (2), 326-349. https://doi.org/10.1177\%2F1524838018767933

*Kupers, T. (2015). A Community Mental Health Model in Corrections. Stanford Law \& Policy Review, 26 (1), 119-158.

Listwan, S.J., Daigle, L. E., Hartman, J. L., \& Guastaferro, W. P. (2014). Poly-Victimization Risk in Prison: The Influence of Individual and Institutional Factors, Journal of Interpersonal Violence, 1-24. https://doi.org/10.1177\%2F0886260513518435

Listwan, S., Hanley, D., \& Colvin, M. (2012). The Prison Experience and Reentry: Examining the Impact of Victimization on Coming Home. Final Report. U.S. Department of Justice: National Institute of Justice.

*Martin, M.S., Wells, G.A., Crocker, A.G., Potter, B.K., \& Colman, I. (2018). Mental Health Screening, Treatment, and Institutional Incidents: A Propensity Score Matched Analysis of Long-Term Outcomes of Screening. International Journal of Forensic Mental Health, 17 (2), 133144. https://doi.org/10.1080/14999013.2018.1451415

McGuire, J. (2018). Understanding prison violence: a rapid evidence assessment. Analytical Summary 2018. HM Prison \& Probation Service. 
Moher, D., Shamseer, L., Clarke, M., Ghersi, D., Liberati, A., Petticrew, M., Shekelle, P., Stewart, L., \& Prisma-P Group. (2015). Preferred reporting items for systematic review and meta-analysis protocols (PRISMA-P) statement. Systematic reviews, 4, 1. https://doi.org/10.1186/2046-4053-41

Papadakaki, M., Tsalkanis, A., Prokopiadou, D., Goutsou, M., \& Chliaoutakis, J. (2019). Is sexual assault a problem in Greek prisons? Initial evidence from a Greek male prison. Safety, 5 (4), 84-100. https://doi.org/10.3390/safety5040084

Reisig, M. (2002). Administrative Control and Inmate Homicide. Homicide Studies, 6, 84-103. https://doi.org/10.1177\%2F1088767902006001005

Sanchez, F. C., \& Wolff, N. (2018). Understanting polyvictimization in prison: Prevalence and predictors among men inmates in Spain. Journal of Interpersonal Violence, $\quad 00 \quad$ (0), https://doi.org/10.1177\%2F0886260518775751

*Sanchez, F. C., \& Wolff, N. (2017). The association between substance use and physical victimization among incarcerated men in Spanish prisons. International Journal Law Psychiatry, 50, 9-16. https://doi.org/10.1016/i.ijlp.2016.09.006

*Sánchez, F. C., \& Wolff, N. (2016). Prevalence and Predictors of Sexual Victimization Among Incarcerated Men and Women in Spanish Prisons. Criminal Justice and Behavior, 43(8), 977-991. https://doi.org/10.1177\%2F0093854816656895

Schappel, A., Docherty, M., \& Boxer, P. (2016). Violence and Victimization During Incarceration: Relations to Psychosocial Adjustment During Reentry to the Community. Violence Victims, 31 (2), 361-378. https://doi.org/10.1891/0886-6708.vv-d-13-00188

Shamseer, L., Moher, D., Clarke, M., Ghersi, D., Liberati, A., Petticrew, M., Shekelle, P., \& Stewart, L.A. the Prisma-P Group (2015). Preferred reporting items for systematic review and meta-analysis protocols
(PRISMA-P) 2015: elaboration and explanation. Research methods \& reporting, 2-25. https://doi.org/10.1136/bmi.g7647

Shubina, I. (2015). Cognitive-behavioral therapy of patients with PTSD: literature review. Social and behavioral Sciences, 165, 208-216. https://doi.org/10.1016/i.sbspro.2014.12.624

Steiner, B., \& Wooldredge, J. (2013). Implications of Different Outcome Measures for an Understanding of Inmate Misconduct. Crime \& Delinquency,$$
\text { (8), }
$$

1234-1262. https://doi.org/10.1177\%2F0011128709335151

Vigne, N., Debus-Sherril, S., Brazzel, D., \& Downey, P.M. (2011). Preventing violence and sexual assault in jail: a situational crime prevention approach. Urban Institute, Justice Policy Center.

Wolff, N., Blitz, C. L., Shi, J., Bachman, R., \& Siegel, J.A. (2006). Sexual violence in prisons: Rates of victimization. Journal of Urban Health: Bulletin of the New York Academy of Medicine, 83(5): 835-848. https://doi.org/10.1007/s11524-006-9065-2

Wolff, N., Blitz, C. L., Shi, J., Siegel, J., \& Bachman, R. (2007). Physical violence inside prisons: Rates of victimization. Criminal Justice and Behavior, 34(5), 588-599. https://doi.org/10.1177\%2F0093854806296830

Wolff, N., Shi, J., \& Bachman, R. (2008). Measuring victimization inside prisons: Questioning the questions. Journal of Interpersonal Violence, 23, 10, 134-1362. https://doi.org/10.1177\%2F0886260508314301

Wolff, N., Shi, J., \& Siegel, J.A. (2009). Patterns of Victimization Among Male and Female Inmates: Evidence of an Enduring Legacy. Violence and Victims, 24, 4, 469-484. https://doi.org/10.1891/08866708.24.4.469

Zweig, J. M., Yahner, J., Visher, C. A., \& Lattimore, P. K. (2015). Using General Strain Theory to Explore the Effects of Prison Victimization Experiences on Later Offending and Substance Use. The Prison Journal, 95(1), 84-113. https://doi.org/10.1177\%2F0032885514563283 